\title{
ChimLeish, a new recombinant chimeric protein evaluated as a diagnostic and prognostic marker for visceral leishmaniasis and human immunodeficiency virus coinfection
}

\author{
Nathalia C. Galvani ${ }^{1}$. Amanda S. Machado ${ }^{1}$. Daniela P. Lage ${ }^{1}$. Camila S. Freitas ${ }^{1}$. Danniele L. Vale ${ }^{1}$. \\ Daysiane de Oliveira ${ }^{2} \cdot$ Fernanda Ludolf $^{1} \cdot$ Fernanda F. Ramos ${ }^{1} \cdot$ Bruna B. Fernandes $^{2}$. Gabriel P. Luiz ${ }^{2}$. \\ Débora V. C. Mendonçaa • João A. Oliveira-da-Silva ${ }^{1}$. Thiago A. R. Reis ${ }^{1}$. Grasiele S. V. Tavares ${ }^{1} \cdot$ Ana T. Chaves ${ }^{1}$. \\ Nathalia S. Guimarães ${ }^{1}$. Unaí Tupinambás ${ }^{1}$. Gláucia F. Cota ${ }^{3}$. Maria V. Humbert ${ }^{4}$. Vívian T. Martins ${ }^{1}$. \\ Myron Christodoulides ${ }^{4}$ Eduardo A. F. Coelho ${ }^{1,5}$ (1) - Ricardo A. Machado-de-Ávila ${ }^{2}$
}

Received: 14 May 2021 / Accepted: 4 October 2021 / Published online: 19 October 2021

( ) The Author(s), under exclusive licence to Springer-Verlag GmbH Germany, part of Springer Nature 2021

\begin{abstract}
Visceral leishmaniasis (VL) is a neglected tropical disease of global importance caused by parasites of the genus Leishmania, and coinfection with human immunodeficiency virus (HIV) is common in countries where both diseases are endemic. In particular, widely used immunological tests for VL diagnosis have impaired sensitivity (Se) and specificity (Sp) in VL/ HIV coinfected patients and there is also cross-reactivity with other endemic diseases, e.g., Chagas disease, malaria, and tuberculosis. To develop new antigens to improve the diagnosis of VL and VL/HIV coinfection, we predicted eight specific B-cell epitopes of four Leishmania infantum antigens and constructed a recombinant polypeptide chimera antigen called ChimLeish. A serological panel of 195 serum samples was used to compare the diagnostic capabilities of ChimLeish alongside the individual synthetic peptides. ChimLeish reacted with sera from all VL and VL/HIV coinfected patients $[$ Se $=$ $100 \% ; \mathrm{Sp}=100 \%$; area under the curve $(\mathrm{AUC})=1.0]$. Peptides showed lower reactivities $(\mathrm{Se}=76.8$ to $99.2 \% ; \mathrm{Sp}=67.1$ to 95.7\%; AUC between 0.87 and 0.98$)$ as did a L. infantum antigenic preparation used as an antigen control $(\mathrm{Se}=56.8 \%$; $\mathrm{Sp}$ $=69.5 \%$ : AUC $=0.45)$. Notably, ChimLeish demonstrated a significant reduction $(p<0.05)$ of anti-ChimLeish antibodies after treatment and cure of a small number of patients. Although only a limited serological panel was tested, preliminary data suggest that ChimLeish should be evaluated in larger sample studies for the diagnosis of VL and VL/HIV coinfection.
\end{abstract}

Keywords Visceral leishmaniasis $\cdot$ Recombinant chimera $\cdot$ Synthetic peptides $\cdot$ Diagnosis $\cdot$ Prognosis $\cdot$ ELISA

\section{Introduction}

Section Editor: Sarah Hendrickx

Myron Christodoulides, Eduardo A. F. Coelho, and Ricardo A. Machado-de-Ávila are co-senior authors of this study.

Eduardo A. F. Coelho

eduardoferrazcoelho@yahoo.com.br

1 Laboratório de Pesquisa do Programa de Pós-Graduação em Ciências da Saúde: Infectologia e Medicina Tropical, Faculdade de Medicina, Universidade Federal de Minas Gerais, Avenida Prof. Alfredo Balena, 190, Belo Horizonte, Minas Gerais 30130-100, Brazil

2 Programa de Pós-Graduação em Ciências da Saúde, Universidade do Extremo Sul Catarinense, Criciúma, Santa Catarina 88806-000, Brazil
Leishmaniases are tropical diseases caused by parasites of the genus Leishmania that affect populations in several countries in the world (WHO, 2018). Infections range from

3 Centro de Pesquisas René Rachou, Fundação Oswaldo Cruz, FIOCRUZ, Belo Horizonte, Minas Gerais, Brazil

4 Neisseria Research Group, Molecular Microbiology, School of Clinical and Experimental Sciences, Faculty of Medicine, University of Southampton, Southampton General Hospital, Southampton SO16 6YD, England, UK

5 Departamento de Patologia Clínica, COLTEC, Universidade Federal de Minas Gerais, Belo Horizonte, Minas Gerais 31270-901, Brazil 
self-limiting cutaneous lesions to fatal visceral, and the presentation depends on the species of the infecting parasite and the host's immunological response (Kevric et al. 2015; Okwor and Uzonna 2016). Visceral leishmaniasis (VL) can be fatal in about $95.0 \%$ of cases, when acute and if untreated (Torres-Guerrero et al. 2017). However, treatment is toxic and expensive and the emergence of resistant strains has been observed. Furthermore, no vaccine is available to protect against human VL (Srivastava et al. 2016; Ponte-Sucre et al. 2017).

Rapid and precise diagnosis of leishmaniases is required, and parasitological tests have been used for this purpose, which have shown high specificity. However, variable sensitivity has been observed, since amastigote forms of the parasite or parasite antigens cannot be found in the collected organ aspirates, leading to false-negative results. Detection of the genetic material of the parasite by polymerase chain reaction (PCR) has improved the diagnosis of VL. PCR has higher sensitivity than the conventional parasitological methods and has been also used in epidemiological studies to detect the parasite in potential vectors and reservoirs (Pereira et al. 2014). However, the need of trained professionals, the high unit cost of PCR tests, and the need for sophisticated equipment, all hamper the large-scale use of this diagnostic technique in resource-limited settings in the least developed and low-to-middle income countries that bear the burden of infections (Srividya et al. 2012; Thakur et al. 2020).

Instead, immunological methods, such as the indirect immunofluorescence reaction (RIFI), enzyme-linked immunosorbent assay (ELISA), direct agglutination test (DAT), immunochromatographic tests (ICTs), among others, have been used as diagnostic test platforms for VL (Sakkas et al. 2016; Mohebali et al. 2020). In these tests, the use of recombinant proteins has improved the sensitivity and specificity of the diagnosis, and a kinesin-related protein called rK39 has been identified as a diagnostic antigen for VL in immunocompetent patients (Maia et al. 2012; Sanchez et al. 2020). rK39 has been used in ELISA assays to examine sera from patients with VL in India, and sensitivity and specificity values of $100 \%$ and $96.0 \%$ were reported, respectively (Mohapatra et al. 2010). In another study that examined sera from Brazilian patients, the rK39 antigen showed sensitivity and specificity values of $90.5 \%$ and $97.9 \%$, respectively (Dhom-Lemos et al. 2019). Other recombinant antigens have been evaluated for diagnosis of VL. The amastigotespecific A2 protein was used in ELISA experiments and results showed 76.0-78.0\% sensitivity to detect VL in Brazilian patients (Carvalho et al. 2002). Other kinesins, such as K9, K26, KE16, and KRP42, have also showed varying potential in diagnosing VL and their performance has varied depending on the study populations (Takagi et al. 2007; Mohapatra et al. 2010; Srividya et al. 2012). For example, the performance of the rK39-based dipstick test to diagnose VL in patients from India, Nepal, and Brazil was high, but the test failed to detect the disease in Sudanese patients (Zijlstra et al. 2001; Singh et al. 2010). Thus, performance of such tests based on these recombinant antigens appears to be compromised by geography and the nature of the study populations.

Notably, coinfection with human immunodeficiency virus (HIV) has caused problems for the diagnosis of VL in patients living in countries where both diseases coexist and are endemic (Coutinho et al. 2017; Mohebali and Yimam 2020). VL is an opportunistic disease in HIV-infected patients (Cipriano et al. 2017) and both pathologies contribute to worsening patient health. In coinfection cases, antiLeishmania antibody levels are found in lower levels to those detected in immunocompetent patients, which reduces the sensitivity of the tests (Cota et al. 2012; Távora et al. 2015). In one study, the performance of distinct immunological tests was evaluated for the diagnosis of VL in Ethiopian patients, as well as those suspected to be infected with HIV. Results showed that sensitivity for VL ranged from 69.2 to $92.2 \%$, whereas the specificity varied widely from 20.0 to $100 \%$. The authors concluded that the sensitivity in the evaluated tests was reduced significantly when samples of VL/ HIV coinfection patients were analyzed (Kassa et al. 2020).

Our hypothesis is that a combination of distinct antigens could reduce the heterogeneity of the patients' individual immune responses and leading to improved sensitivity and specificity for the diagnosis of VL and VL/HIV coinfection. Previously, we have shown that specific B-cell epitopes of four L. infantum proteins, called $\mathrm{LiHyT}$, LiHyD, $\mathrm{LiHyV}$, and LiHyP, were previously showed to be antigenic in canine and/or human VL (Coelho et al. 2012; Martins et al. 2015; Lage et al. 2016; Portela et al. 2018). In the present study, we constructed a recombinant chimeric protein called ChimLeish based on B-cell epitopes from these parasite proteins in order to examine its potential for the diagnosis of VL and VL/HIV coinfection. The efficacy of ChimLeish was evaluated using a serological panel from VL and VL/HIV patients, and its prognostic activity was investigated using sera samples from VL patients collected before and after treatment.

\section{Materials and methods}

\section{Parasites}

L. infantum (MHOM/BR/1970/BH46) stationary promastigotes were grown in Schneider's medium (Sigma, St. Louis, MO, USA) supplemented with $20 \%(\mathrm{v} / \mathrm{v})$ inactivated fetal bovine serum (FBS, Sigma), $20 \mathrm{mM}$ L-glutamine, $200 \mathrm{U} / \mathrm{mL}$ penicillin, and $100 \mu \mathrm{g} / \mathrm{mL}$ streptomycin, $\mathrm{pH} 7.4$, at $24{ }^{\circ} \mathrm{C}$. 
The soluble Leishmania antigen extract (SLA) was prepared as described previously (Coelho et al. 2003), by growing $10^{9}$ stationary promastigotes and disrupting them with six alternate cycles of freezing and thawing in liquid nitrogen and a water bath, respectively, followed by sonication with six cycles of $30 \mathrm{~s}$ at $38 \mathrm{MHz}$ in an ultrasonic processor (GEX600 model). The lysate was centrifuged at $10,000 \times g$ for $15 \mathrm{~min}$ at $4{ }^{\circ} \mathrm{C}$ and the supernatant containing SLA was collected and stored at $-70{ }^{\circ} \mathrm{C}$ until use.

\section{Sera samples}

The study was approved by the Ethics Committee of the Federal University of Minas Gerais (UFMG; Belo Horizonte, Minas Gerais, Brazil) with protocol number CAAE32343114.9.0000.5149. All patients received an individual copy of the study policy, which was reviewed by an independent person. Written consent was obtained from all patients. Sera were collected from VL $(n=45$, including 28 males and 17 females, with ages ranging from 27 to 64 years), VL/HIV coinfected ( $n=25$, including 17 males and 8 females, with ages ranging from 31 to 55 years), and HIVinfected ( $n=20$, including 13 males and 7 females, with ages ranging from 22 to 50 years) patients. The diagnosis of VL was confirmed by clinical evaluation and positive result for detection of $L$. infantum kDNA in spleen and/or bone marrow aspirates of the patients by PCR technique (Cota et al. 2013). HIV infection was based on clinical evaluation, $\mathrm{CD}^{+} \mathrm{T}$ cell count and viral load in the patients. None of the patients was receiving any VL treatment before sample collection. Sera were also collected from healthy individuals living in an endemic region for VL $(n=45$, including 26 males and 19 females, with ages ranging from 23 to 57 years; Belo Horizonte). They did not present with any clinical signs or suspicion of leishmaniasis and showed negative serological result using a commercial test (Kalazar Detect ${ }^{\mathrm{TM}}$ Test, InBios International, Inc., Seattle, WA, USA). In addition, sera samples from patients with Chagas disease $(n=$ 40, including 26 males and 14 females, with ages ranging from 27 to 52 years), tuberculosis ( $n=10$, including 6 males and 4 females, with ages ranging from 27 to 57 years), and malaria ( $n=10$, including 7 males and 3 females, with ages ranging from 35 to 64 years) were used also in the ELISA experiments.

\section{Sera samples collected before and after VL treatment}

Sera were also collected from VL patients $(n=6$, including 4 males and 2 females, with ages ranging from 33 to 61 years), before and 6 months after treatment with pentavalent antimonials (Sanofi Aventis Farmacêutica Ltda., Suzano, São Paulo, Brazil). Patients received the same therapeutic regimen of a dose of $20 \mathrm{mg} \mathrm{Sb}{ }^{+5}$ per $\mathrm{kg}$ for 30 days. None of the patients suffered from any other infection or had any pre-existing disease(s).

\section{Construction of ChimLeish protein}

To select the specific B-cell epitopes of LiHyT (XP_001465138.1), LiHyD (XP_001468360.1), LiHyV (XP_001462854.1), and LiHyP (XP_001468385.2) proteins, their primary structure was evaluated using the SwissProt server (web.expasy.org/docs/swiss-prot), and their amino acid sequences were saved as .TXT files. The IEDB server (www.iedb.org) was then used to identify the amino acid sequences most likely to be accessible, with the parameters of window size of 12 and a threshold of 1.0. The sequences identified were marked in the protein structure. The epitopes were predicted using the ABCpred (www.imtech.res.in/ raghava/abcpred/) server using the parameters of window size of 16 and a threshold of 0.85 . The selected sequences were marked in the protein structure (Saha and Raghava 2006). The amino acids identified in both analyses were used to construct the target peptide sequence. The ProtParam server (Gasteiger et al. 2005) was used to obtain the physical-chemical characteristics of the chimera, while the PepCalc server (www.pepcalc.com) was used to evaluate the protein solubility.

\section{Production of the recombinant ChimLeish protein and peptides}

The selected B-cell epitopes were used to construct the ChimLeish-encoding gene, which was cloned commercially into the pET28a-TEV vector (Genscript ${ }^{\circledR}$, USA). The gene was inserted into E. coli Arctic Express (DE3) cells and protein expression was induced with $1.0 \mathrm{mM}$ isopropyl$\beta$-D-thiogalactopyranoside (IPTG, Promega ${ }^{\circledR}$, Canada), for $2 \mathrm{~h}$ at $37^{\circ} \mathrm{C}$. Cells were centrifuged at $3,000 \times g$ for 10 min at $4{ }^{\circ} \mathrm{C}$ and disrupted using seven cycles of ultrasonication, with cycles of $30 \mathrm{~s}$ each $(36 \mathrm{MHz})$, followed by six cycles of freezing and thawing. Cellular debris was removed after centrifugation $\left(5,000 \times g\right.$ for $15 \mathrm{~min}$ at $\left.4{ }^{\circ} \mathrm{C}\right)$, and the recombinant protein was purified on a HisTrap HP affinity column (GE Healthcare Life Sciences, NJ, USA) connected to an AKTA system. The eluted fractions were concentrated using Amicon ${ }^{\circledR}$ ultra15 filters with nominal molecular weight limit of 10,000 (NMWL, Millipore, Germany), and then purified on a Superdex ${ }^{\mathrm{TM}} 200$ gel filtration column (GE Healthcare, USA). After dialysis, ChimLeish was passed through a polymyxin-agarose column (SigmaAldrich, USA) in order to remove any residual endotoxin content $(<10 \mathrm{ng}$ of LPS per $1 \mathrm{mg}$ of recombinant protein, measured by the Quantitative Chromogenic Limulus Amebocyte Assay QCL-1000 kit, BioWhittaker, MD, USA). In 
addition, the eight individual epitopes were synthesized by F-moc technique (Machado-de-Ávila et al. 2011). Briefly, peptides were released from the amine resin by trifluoroacetic acid treatment in the presence of the appropriate scavengers and diluted in milli-Q water. They were then purified by high-performance liquid chromatography on a C18 reverse phase column with flow rate $1.0 \mathrm{~mL} / \mathrm{min}$. The synthetized peptides were then submitted to a MALDI-TOFTOF assay to evaluate their purity.

\section{Immunological assays}

Titration curves were done to determine the most appropriate antigen concentration and antibody dilution to be used in the ELISA assays. Thus, microtiter immunoassay plates (Jetbiofil ${ }^{\circledR}$, Belo Horizonte) were coated with the synthetic peptides, ChimLeish, and SLA (at 5.0, 0.250, and $1.0 \mu \mathrm{g}$ per well, respectively) diluted in coating buffer $(50 \mathrm{mM}$ carbonate buffer, $\mathrm{pH}$ 9.6), and incubated for $16 \mathrm{~h}$ at $4{ }^{\circ} \mathrm{C}$. Next, free binding sites were blocked with PBS-T (PBS plus 0.05\% (v/v) Tween-20) added with 5\% (w/v) bovine serum albumin for $1 \mathrm{~h}$ at $37^{\circ} \mathrm{C}$. Plates were washed five times with PBS-T and incubated with human sera (1:100 dilution in PBS-T for the peptides and SLA or 1/200 dilution in PBS-T for the ChimLeish) for $1 \mathrm{~h}$ at $37^{\circ} \mathrm{C}$. Plates were washed seven times in PBS-T and incubated with anti-human IgG peroxidase conjugated antibody (1/10,000 dilution in PBS-T for the peptides and SLA or 1/20,000 dilution in PBS-T for ChimLeish) for $1 \mathrm{~h}$ at $37^{\circ} \mathrm{C}$. Plates were then washed six times with PBS-T, and reactions were developed by incubation with a solution composed by $\mathrm{H}_{2} \mathrm{O}_{2}$, ortho-phenylenediamine, and citrate-phosphate buffer $\mathrm{pH}$ 5.0, for $30 \mathrm{~min}$ in the dark. They were then stopped by addition of $2 \mathrm{~N} \mathrm{H}_{2} \mathrm{SO}_{4}$ and the optical density (OD) values were read in an ELISA microplate spectrophotometer (Molecular Devices, Spectra Max Plus, Canada) at $\lambda 492 \mathrm{~nm}$. All samples were tested on the same day and using the same reagents to reduce experimental variation. In addition, the humoral reactivity was analyzed using samples of VL and VL/HIV coinfected patients against a commercial kit (Kalazar Detect ${ }^{\mathrm{TM}}$ Test), which was used according the manufacturer's instructions (InBios International, USA).

\section{Statistical analysis}

Results were entered into Microsoft Excel (version 10.0) spreadsheets and analyzed using GraphPad PrismTM (version 6.0 for Windows). Receiver operating characteristic (ROC) curves were constructed to obtain the cut-off values, as well as sensitivity (Se), specificity ( $\mathrm{Sp}$ ), positive predictive value (PPV), negative predictive value (NPV), and area under the curve (AUC) of the antigens. The one-way analysis of variance (ANOVA) was used for comparison between groups. The cut-off was determined through the mean of the negative samples plus two standard deviation. Confidence intervals with a 95\% level (95\% CI) and Youden index $[$ (sensitivity + specificity $)-1]$ evaluated the antigen performance. Differences were significant with $p$ values $<0.05$.

\section{Results}

\section{Characterization of the recombinant ChimLeish protein}

Eight specific B-cell epitopes were predicted in the amino acid sequences of the LiHyT, LiHyD, LiHyP, and LiHyV proteins, with two linear epitopes selected for each protein (Table 1). The epitopes were combined in a single sequence with the addition of two glycine residues between them, in order to provide flexibility and avoid spatial overlap (Mendes et al. 2013; Lima et al. 2018). In addition, the epitope position was defined according to its original position in the native protein sequence, i.e., those near the $\mathrm{N}$-terminus were maintained in this position, while the others near the $\mathrm{C}$-terminus were maintained in this position in the chimera sequence. The arrangement of the amino acid sequences in the recombinant chimeric protein ChimLeish is shown in
Table 1 Amino acid sequences of identified B-cell epitopes

\begin{tabular}{lll}
\hline Antigen & Origin protein & Amino acid sequence \\
\hline Pept1 & LiHyT (XP_001465138.1) & KLTSMTPHEFKAICRL \\
Pept2 & LiHyT (XP_001465138.1) & RVQATEAQDRDLYARF \\
Pept3 & LiHyD (XP_001468360.1) & PELYQQYVDYYVMYYE \\
Pept4 & LiHyD (XP_001468360.1) & EPLLQQTQRAHMQRQQPAMPQPGYQPPPPM \\
Pept5 & LiHyV (XP_001462854.1) & SQGASSGTCANAKCIPGNT \\
Pept6 & LiHyV (XP_001462854.1) & SSFPITKGAALTVDYGRCE \\
Pept7 & LiHyP (XP_001468385.2) & EETIRRRHEQRAARVK \\
Pept8 & LiHyP (XP_001468385.2) & PRRLAAADLEELASAHEDFVAHLEKAKER \\
\hline
\end{tabular}

The amino acid sequences of the identified B-cell epitopes in the LiHyT, LiHyV, LiHyD, and LiHyP proteins are shown, as well as the corresponding proteins used to identify the epitopes 
Fig. 1. Physical-chemical characterization of ChimLeish calculated a molecular weight of $19.2 \mathrm{kDa}$, an isoelectric point of 8.1, an estimated half-life of $30 \mathrm{~min}$ in yeasts and higher than $10 \mathrm{~h}$ in E. coli, and an aliphatic index of 54.8 suggesting that it is a stable protein. The solubility analysis identified hydrophilic amino acids in the protein sequence, suggesting that ChimLeish is also a soluble molecule.

\section{Diagnostic evaluation of the distinct antigens}

An immunological evaluation to diagnose VL and VL/HIV coinfection cases was done using the synthetic peptides (Pept1 to Pept8), ChimLeish, and SLA as antigens in ELISA experiments. Results showed that all VL and VL/HIV coinfected patients' sera presented individual OD values significantly above the cut-off $(p<0.05)$, when ChimLeish was used as the antigen in the assays (Fig. 2). In addition, sera from patients with Chagas disease, tuberculosis, or malaria and from healthy individuals, all had OD values below of the cut-off and were not significant $(p>0.05)$. Furthermore, most of the VL and VL/HIV coinfected patient serum samples had OD values above of the cut-off when tested against the individual synthetic peptides; however, some minor cross-reactivity was observed for some of the peptides with other non-VL, non-VL/HIV sera, e.g., with sera from Chagas patients with Pept2, 4, 5, and 8 (Fig. 2). ROC curves were constructed using the OD values for the antigens and the results are shown in Fig. 3. The sensitivity and specificity values for ChimLeish were $100 \%$, respectively, with AUC value of 1.0. Conversely, the sensitivity values for the synthetic peptides varied from 76.8 to $99.2 \%$, and the specificity ranged from 67.1 to $95.7 \%$ (Table 2). The AUC values varied from 0.87 to 0.98 . The SLA preparation showed sensitivity and specificity values of $56.8 \%$ and $69.5 \%$, respectively, and AUC of 0.45 .

\section{Humoral reactivity of VL and VL/HIV sera against a commercial kit}

Samples of VL and VL/HIV coinfected patients $(n=25$ each), which were all reactive with ChimLeish, were also tested with the Kalazar Detect ${ }^{\mathrm{TM}}$ Test kit. Results showed that the kit detected 20 of 25 (80.0\%) VL and 12 of 25 (48.0\%) VL/HIV coinfected patients' sera, while five of 25 (20.0\% cases) VL and 13 of 25 (52.0\% cases) VL/HIV patients' sera were classified as false-negatives.

\section{Antibody response before and after VL treatment}

The humoral reactivity of VL patient sera $(n=6)$ was evaluated before and after treatment in the ELISA assays with the synthetic peptides, ChimLeish, and L. infantum SLA used as antigens. With ChimLeish, there was a significant $\sim 80.0 \%$ reduction in OD after treatment $(p<0.05)$ (Fig. 4A), whereas using the synthetic peptides, the reduction in OD values was lower and ranged from $\sim 10.0 \%$ for Pept $5 ; \sim 30.0 \%$ for Pept6, 7, and 8; and 40.0-50.0\% for Pept1, 2, 3, and 4. By contrast, there was no significant difference when SLA was used as the antigen, as expected ( $p>0.05$, Fig. 4A). These data were paralleled by the calculations of the IgG levels before and after treatment (Fig. 4B). Thus, the highest ratio was shown with ChimLeish as the ELISA antigen (6-fold), and the IgG ratios with the synthetic peptides more variable, ranging from 2 to 4 . By contrast, the $\mathrm{IgG}$ ratio with SLA as antigen was unchanged after treatment (Fig. 4B).

\section{Discussion}

In a recent immunoproteomic study performed with $L$. infantum species, parasite antigenic proteins were recognized by antibodies in sera from dogs with VL (Coelho et al. 2012), and some of these were later cloned and evaluated as recombinant versions for the diagnosis of leishmaniasis, e.g., LiHyT (Portela et al. 2018), LiHyD (Lage et al. 2016), LiHyV (Martins et al. 2015), and LiHyP (Coelho

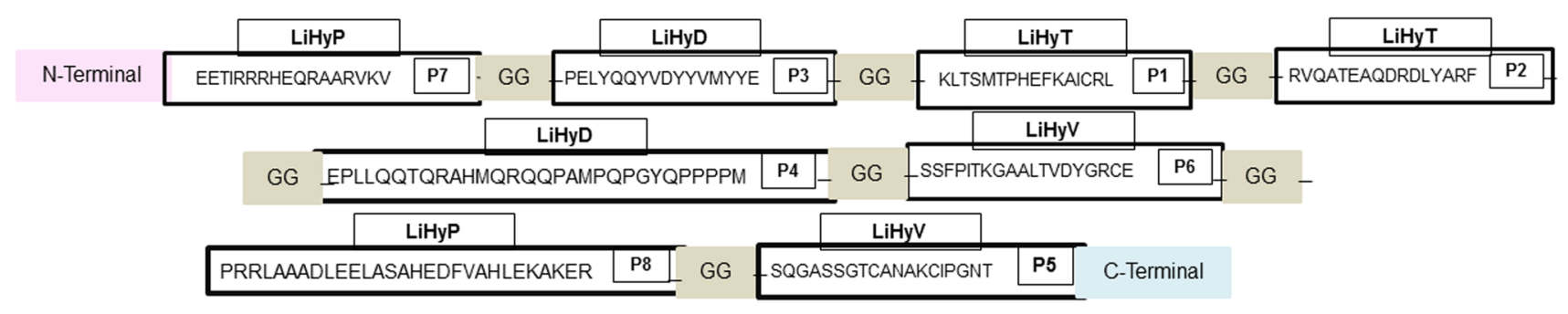

Fig. 1 Alignment of the eight B-cell epitopes to construct ChimLeish. The linear epitopes of the LiHyT, LiHyV, LiHyD, and LiHyP proteins were predicted and the sequences were linearly grouped with a spacing of two glycine (-GG-) residues between them. The complete polypeptide sequence is shown 
Pept 1

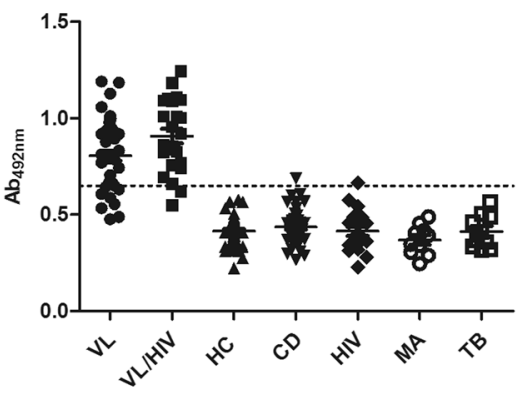

Pept 4

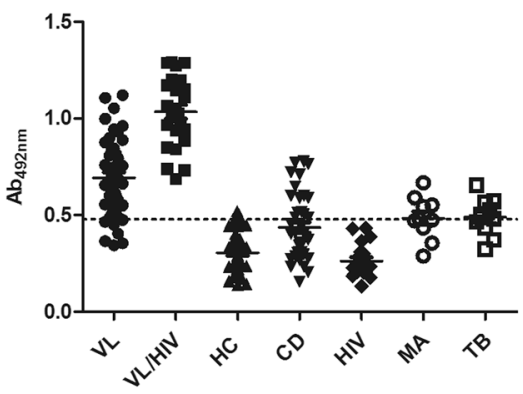

Pept 7

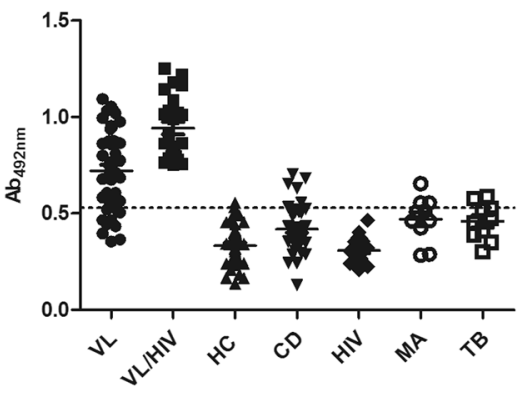

Pept 2

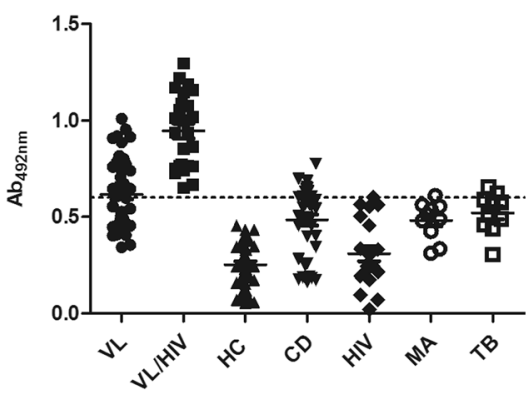

Pept 5

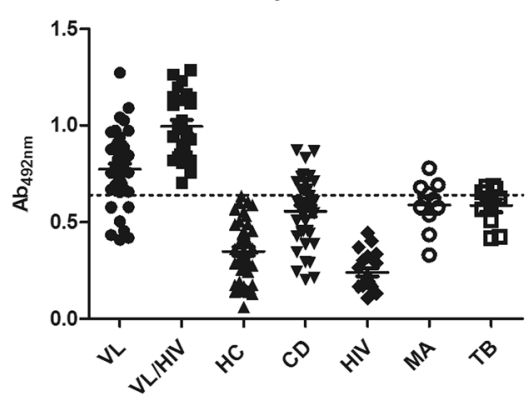

Pept 8

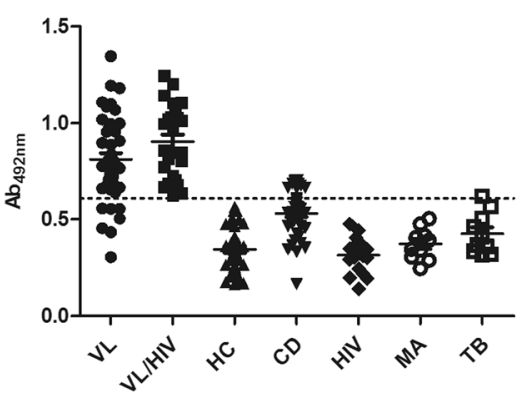

Pept 3

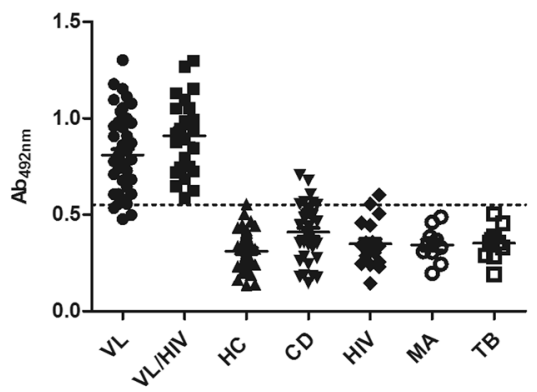

Pept 6

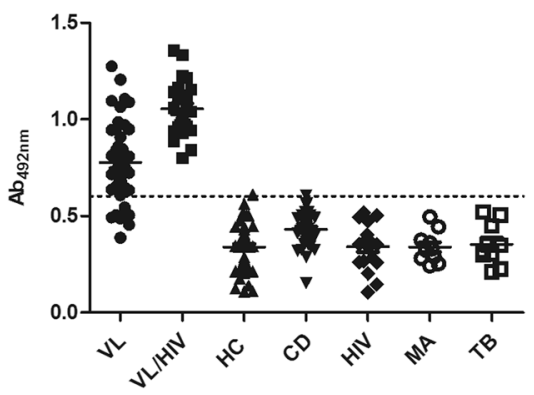

ChimLeish

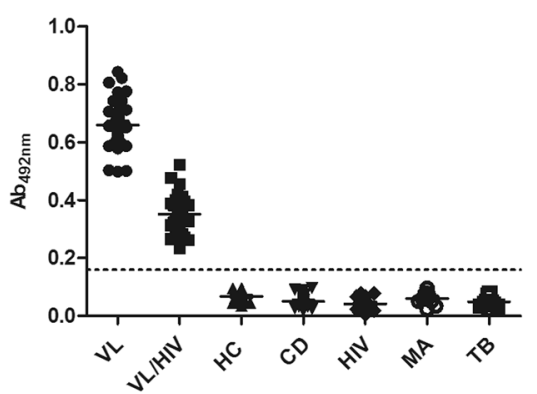

Fig. 2 Serological evaluation of the synthetic peptides and ChimLeish. ELISA experiments were performed using the individual synthetic peptides and ChimLeish with serum samples from patients with visceral leishmaniasis (VL; $n=45)$, VL/HIV coinfection $(n=25)$, HIV infection $(n=20)$, Chagas disease (CD; $n=40)$, tuberculosis

et al. 2012). Commercial diagnostic kits offer good sensitivity and specificity to detect immunocompetent patients, but their performance depends on factors such as the nature of the produced detection antigen, geography, and the study population. In addition, detection of VL/HIV coinfection cases is lower with such kits due to the presence of lower amounts of specific antibodies (Lindoso et al. 2014; Kassa et al. 2020). Therefore, the identification and/or development of more refined diagnostic antigens would be desirable to overcome these limitations. In the present study, we developed a new recombinant chimera protein, ChimLeish, by combining the main linear B-cell epitopes predicted in the amino acid sequences of the LiHyT, LiHyD, LiHyV, and LiHyP proteins. ChimLeish was used in an ELISA platform
(TB; $n=10$ ), and malaria (MA; $n=10$ ) and from healthy individuals living in endemic region of disease (HC; $n=45)$. The cut-off values (horizontal dotted lines) were determined by receiver operator curves (ROC) analysis

to diagnose VL and VL/HIV coinfection and it was compared with synthetic peptide versions of the individual B-cell epitopes and with a soluble parasite antigen preparation. The major findings from our study were that ChimLeish showed the highest sensitivity and specificity values for the diagnosis of VL and for VL in HIV coinfected patient sera, when compared to the other antigens and a commercial test, as well as presented no cross-reactivity with sera from patients with other endemic diseases, e.g., Chagas disease, tuberculosis, or malaria or with sera from healthy individuals.

The literature contains a variety of recombinant antigens that have been tested for the diagnosis of VL, although with reports of variable performance, as a consequence of the nature of the antigen used, the duration of infection, the host 

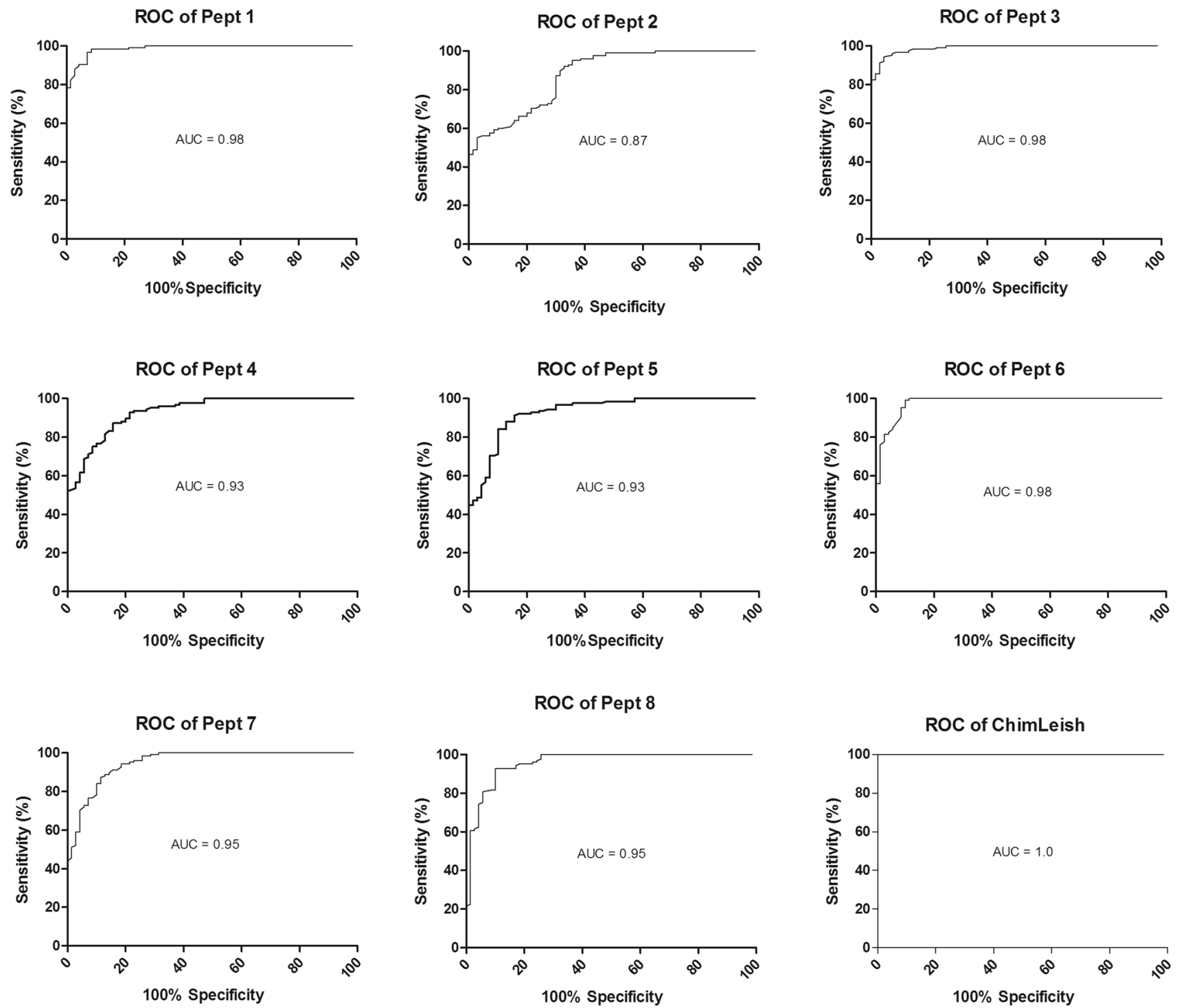

Fig. 3 Receiver operator curves (ROC) analysis. ELISA experiments using the synthetic peptides and ChimLeish were performed with the human serological panel and the individual optical density (OD) val-

immune status, and the presence of coinfections (Sakkas et al. 2016; Sarkari et al. 2018). In our study, ChimLeish showed $100 \%$ sensitivity and specificity for VL diagnosis. Recently, another recombinant chimeric protein called Q5 when used in ELISA showed sensitivity and specificity values of $82.0 \%$ and $100 \%$, respectively, for VL diagnosis (Santos et al. 2020). Figueiredo et al. (2021) developed a recombinant chimeric protein called DTL-4 and when used in ELISA, this antigen presented sensitivity and specificity values of $94.6 \%$ and $99.4 \%$, respectively. Taken together, our current study, supported by these additional studies, suggests that polypeptide-based recombinant antigens are promising candidates for the serodiagnosis of VL. Indeed, their levels of performance appear to exceed those reported for some ues were used to calculate the ROC curves. Results for each antigen are shown

other potential individual antigens. For example, the recombinant $\mathrm{H} 2 \mathrm{~B}$ antigen was cloned from an Iranian isolate of $L$. infantum and tested with sera from VL patients, from healthy controls living in endemic and non-endemic areas of VL, and from patients with cross-reactive diseases. Recombinant H2B antigen showed sensitivity and specificity values of $71.3 \%$ and $69.6 \%$, respectively, for VL diagnosis (Rezaei et al. 2019). In another study, three Leishmania hypothetical proteins called $\mathrm{C} 1, \mathrm{C} 8$, and $\mathrm{C} 9$ were also produced as recombinant proteins and tested as diagnostic antigens for human VL. Recombinant C1, C2, and C9 proteins presented sensitivity values of $66.2 \%, 58.2 \%$, and $67.9 \%$, respectively, and specificity values of $60.0 \%, 50.0 \%$, and $77.7 \%$, respectively (Fonseca et al. 2014). 
Table 2 Evaluation of the synthetic peptides and ChimLeish for the diagnosis of VL and VL/HIV coinfection

\begin{tabular}{llllllllllll}
\hline Antigen & \multicolumn{1}{l}{ Parameters } & \multicolumn{10}{l}{} \\
\cline { 2 - 10 } & Sensitivity & $95 \%$ CI & Specificity & 95\%CI & AUC & Cut-off & $p$ value & PPV & NPV & Y \\
\hline ChimLeish & 100 & $97.1-100$ & 100 & $94.8-100$ & 1.0 & $<0.160$ & $<0.0001$ & 1.0 & 1.0 & 1.0 \\
Pept1 & 98.4 & $94.3-99.8$ & 81.4 & $70.3-89.7$ & 0.98 & $<0.660$ & $<0.0001$ & 0.83 & 0.98 & 0.79 \\
Pept2 & 91.2 & $84.8-95.5$ & 67.1 & $54.9-77.9$ & 0.87 & $<0.600$ & $<0.0001$ & 0.68 & 0.88 & 0.58 \\
Pept3 & 94.4 & $88.8-97.7$ & 95.7 & $88.0-99.1$ & 0.98 & $<0.550$ & $<0.0001$ & 0.96 & 0.93 & 0.89 \\
Pept4 & 76.8 & $68.4-83.9$ & 90.0 & $80.5-95.9$ & 0.93 & $<0.480$ & $<0.0001$ & 0.90 & 0.74 & 0.66 \\
Pept5 & 84.0 & $76.4-89.9$ & 90.0 & $80.5-95.9$ & 0.93 & $<0.650$ & $<0.0001$ & 0.90 & 0.84 & 0.74 \\
Pept6 & 99.2 & $95.6-100$ & 90.0 & $80.5-95.9$ & 0.98 & $<0.600$ & $<0.0001$ & 0.90 & 0.98 & 0.89 \\
Pept7 & 91.2 & $84.8-95.5$ & 84.3 & $73.6-91.9$ & 0.95 & $<0.530$ & $<0.0001$ & 0.85 & 0.91 & 0.75 \\
Pept8 & 92.0 & $85.8-96.1$ & 90.0 & $80.5-95.9$ & 0.95 & $<0.610$ & $<0.0001$ & 0.90 & 0.91 & 0.82 \\
SLA & 56.8 & $49.0-69.8$ & 69.5 & $57.7-80.7$ & 0.45 & $<0.544$ & 0.1022 & 0.52 & 0.65 & 0.32 \\
\hline
\end{tabular}

ELISA experiments were performed using the synthetic peptides, ChimLeish, and L. infantum SLA as antigens with sera from patients with visceral leishmaniasis (VL; $n=45)$, VL/HIV coinfected $(n=25)$, HIVinfected $(n=20)$, Chagas disease (CD; $n=40)$, tuberculosis (TB; $n=10)$, and malaria (MA; $n=10)$ and sera from healthy individuals living in endemic region of disease $(n=45)$. The sensitivity, specificity, area under the curve (AUC), positive predictive value (PPV), negative predictive value (NPV), and Youden index $(\mathrm{Y})$ were determined. The confidence interval $(95 \% \mathrm{CI})$ and $p$ value were also calculated and results are shown
HIV coinfection presents an additional challenge for VL diagnosis. When associated with Leishmania infection, it can reduce anti-leishmanial serology in coinfected patients and decrease the sensitivity of VL tests (Rezaei et al. 2018). Notably, in our present study, ChimLeish showed $100 \%$ sensitivity to detect VL/HIV coinfection cases and this level of performance is better than that reported for other potential diagnostic antigens. For example, the recombinant Lci2 and K39 antigens were tested for the diagnosis of VL and VL/ HIV coinfection, and the antigens showed similar sensitivity $(92.0 \%)$ for the diagnosis of VL, although a significant drop $(32.0 \%)$ was found when coinfection cases were evaluated in the ELISA experiments (Ramos et al. 2021). Figueiredo et al. (2021) tested samples of VL/HIV coinfected patients on their DTL-4 antigen in ELISA, and a sensitivity value of $77.4 \%$ was found, which was also a significant reduction when compared to the values obtained with sera from immunocompetent patients.

Small synthetic peptides have been also tested for the diagnosis of VL, with the rationale that a judicious selection of the core antigenic parts of the native proteins could both refine and reduce the variability of the patients' humoral response (Fargeas et al. 1996; Costa et al. 2017). Synthetic peptides have the advantage of being more simple and cheaper to produce than recombinant proteins (Costa et al. 2012). In our study, the eight peptides showed sensitivity values from 76.8 to $99.2 \%$, and specificity values from 67.1 to $95.7 \%$. Although the individual peptides showed a good, though variable, level of performance to detect active disease, none matched the performance of ChimLeish. Furthermore, much higher concentration of the individual peptides was required $(5.0 \mu \mathrm{g} /$ well $)$ for ELISA, compared with ChimLeish $(0.25 \mu \mathrm{g} /$ well $)$, making the latter more costeffective for routine use and population studies.

The long-term persistence of anti-leishmanial serology found in most treated patients is a confounding issue for monitoring the patient response to therapy and as a control of clinic cure (Almeida-Silva et al. 2006; Hasker et al. 2014; Dias et al. 2018). In the present study, we observed a significant reduction in anti-ChimLeish antibody levels in a small number of samples from patients collected at 6 months after treatment. By contrast, Mollett et al. (2019) evaluated anti-rK39 IgG antibody levels in serum samples collected before and after therapy from VL patients in India and found that there were no differences in humoral reactivity in a rK39-based ELISA. The authors concluded that serum reactivity with $\mathrm{rK} 39$ may not be a suitable clinical cure criterion for VL. Alternatively, a flow cytometry-based strategy has been developed as a tool for cure assessment of VL, using samples collected 12 months after treatment, and proved to be highly effective in differentiating negative from positive samples (Lemos et al. 2007). However, this strategy is unlikely to be used in resource-limited settings due to the high cost of cytometers and reagents.

Our study has some limitations. First of all, the absence of higher and diverse serological panels to include more samples from tegumentary leishmaniasis patients and from other cross-reactive diseases. Much larger sample sizes would also be useful to confirm the prognostic role of ChimLeish and further evaluate its suitability for monitoring patient clinical cure. Secondly, the use of a soluble parasite antigenic preparation as a control antigen in not wholly appropriate and other antigens, such as rK39, used in commercial diagnostic tests for VL, should 


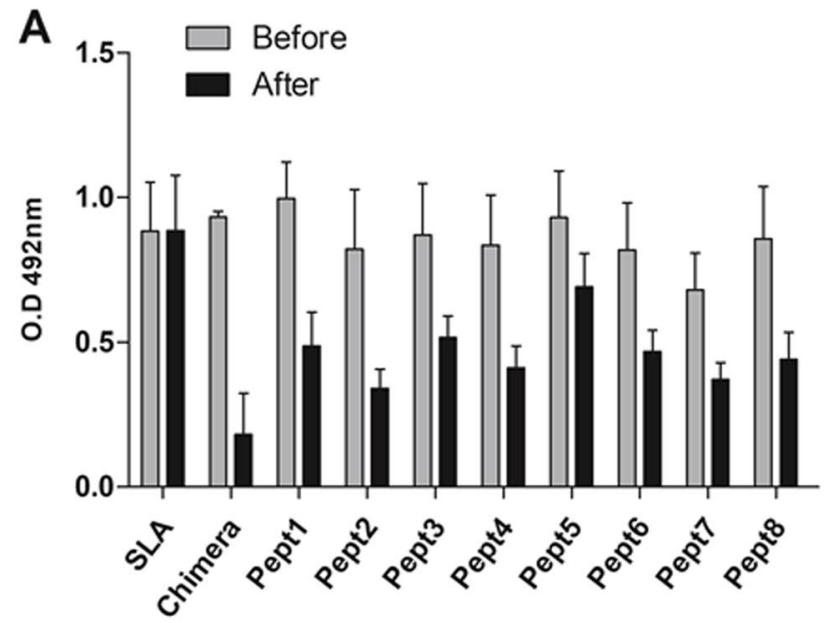

B

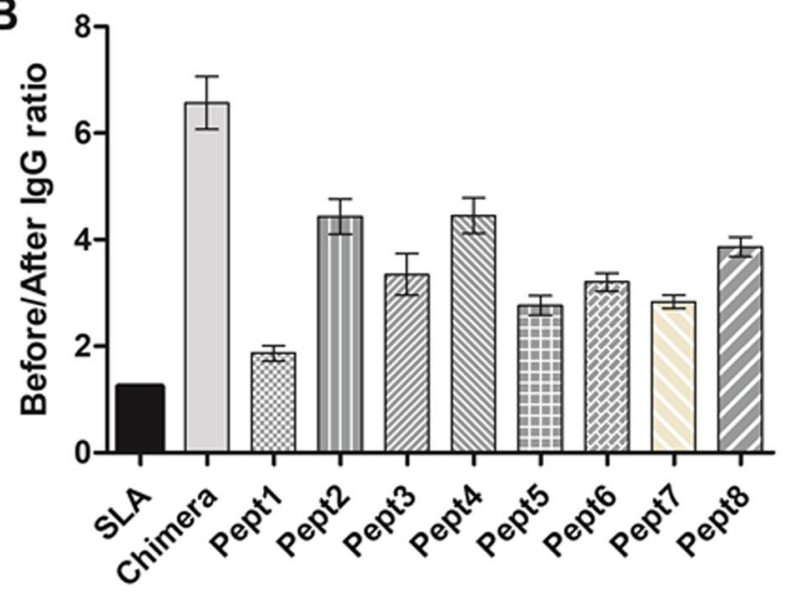

Fig. 4 Humoral reactivity evaluated after VL treatment. The antibody response specific to synthetic peptides and ChimLeish was evaluated in VL patients $(n=6)$, before and 6 months after treatment. The gray and black bars indicate the mean plus standard deviation of the optical density (OD) values observed in the samples collected before and after treatment, respectively (A). In addition, the ratio between antibody levels before and after treatment was calculated (B)

be considered. In summary, our data should be considered as providing proof-of-concept of ChimLeish for VL diagnosis. They suggest that ChimLeish deserves to be evaluated in large populations in future studies, and that its suitability as a diagnostic antigen should also be examined in other platforms, e.g., in rapid point-of-care lateral flow tests (Humbert et al. 2019).

Acknowledgements This work was supported by grant MR/R005850/1 from the Medical Research Council (VAccine deveLopment for complex Intracellular neglecteD pAThogEns-VALIDATE), UK, and grant APQ-408675/2018-7 from the Conselho Nacional de Desenvolvimento Científico e Tecnológico (CNPq), Brazil. The authors also thank the Brazilian agencies Coordenação de Aperfeiçoamento de Pessoal de Nível Superior (CAPES), CNPq and the Fundação de Amparo à Pesquisa do Estado de Minas Gerais (FAPEMIG) for the student scholarships.

\section{Declarations}

Conflict of interest The authors declare no competing interests.

\section{References}

Almeida-Silva L, Romero HD, Prata A, Costa RT, Nascimento E, Carvalho SF, Rodrigues V (2006) Immunologic tests in patients after clinical cure of visceral leishmaniasis. Am J Trop Med Hyg 75:739-43

Carvalho FA, Charest H, Tavares CA, Matlashewski G, Valente EP, Rabello A, Gazzinelli RT, Fernandes AP (2002) Diagnosis of American visceral leishmaniasis in humans and dogs using the recombinant Leishmania donovani A2 antigen. Diagn Microbiol Infect Dis 43:289-295

Cipriano P, Miranda AC, Antunes I, Mansinho K (2017) Visceral leishmaniasis in HIV-infected patients: the challenge of relapse and treatment failure. Acta Med Port 30:443-448

Coelho EAF, Tavares CAP, Carvalho FAA, Chaves KF, Teixeira KN, Rodrigues RC, Charest H, Matlashewski G, Gazzinelli RT, Fernandes AP (2003) Immune responses induced by the Leishmania (Leishmania) donovani A2 antigen, but not by the LACK antigen, are protective against experimental Leishmania (Leishmania) amazonensis infection. Infect Immun 71:3988-3994

Coelho VTS, Oliveira JS, Valadares DG, Chávez-Fumagalli MA, Duarte MC, Lage PS, Soto M, Santoro MM, Tavares CA, Fernandes AP, Coelho EA (2012) Identification of proteins in promastigote and amastigote-like Leishmania using an immunoproteomic approach. PLoS Negl Trop Dis 6:e1430

Costa MM, Penido M, Santos MS, Doro D, Freitas E, Michalick MS, Grimaldi G, Gazzinelli RT, Fernandes AP (2012) Improved canine and human visceral leishmaniasis immunodiagnosis using combinations of synthetic peptides in enzyme-linked immunosorbent assay. PLoS Negl Trop Dis 6:e1622.

Costa LE, Salles BCS, Santos TTO, Ramos FF, Lima MP, Lima MIS, Portela ÁSB, Chávez-Fumagalli MA, Duarte MC, Menezes-Souza D, Machado-de-Ávila RA, Silveira JAG, Magalhães-Soares DF, Goulart LR, Coelho EAF (2017) Antigenicity of phage clones and their synthetic peptides for the serodiagnosis of canine and human visceral leishmaniasis. Microb Pathog 110:14-22

Cota GF, Sousa MR, Demarqui FN, Rabello A (2012) The diagnostic accuracy of serologic and molecular methods for detecting visceral leishmaniasis in HIV infected patients: meta-analysis. PLoS Negl Trop Dis 6:e1665.

Cota GF, Sousa MR, Freitas BMN, Gomes LI, Oliveira E, Assis TS, Mendonça AL, Pinto BF, Saliba JW, Rabello A (2013) Comparison of parasitological, serological, and molecular tests for visceral leishmaniasis in HIV-infected patients: a cross-sectional delayedtype study. Am J Trop Med Hyg 89:570-577

Coutinho JVSC, Santos FSD, Ribeiro RDSP, Oliveira IBB, Dantas VB, Santos ABFS, Tauhata JR (2017) Visceral leishmaniasis and leishmaniasis-HIV coinfection: comparative study. Rev Soc Bras Med Trop 50:670-674

Dhom-Lemos L, Viana AG, Cunha JLR, Cardoso MS, Mendes TAO, Pinheiro GRG, Siqueira WF, Lobo FP, Teles LF, Bueno LL, Guimarães-Carvalho SF, Bartholomeu DC, Fujiwara RT (2019) Leishmania infantum recombinant kinesin degenerated derived repeat (rKDDR): a novel potential antigen for serodiagnosis of visceral leishmaniasis. PLoS One 14:e0211719.

Dias DS, Ribeiro PAF, Salles BCS, Santos TTO, Ramos FF, Lage DP, Costa LE, Portela ASB, Carvalho GB, Chávez-Fumagalli MA, Caligiorne RB, Oliveira JS, Magalhães-Soares DF, Silva ES, Galdino AS, Menezes-Souza D, Duarte MC, Gonçalves 
DU, Coelho EAF (2018) Serological diagnosis and prognostic of tegumentary and visceral leishmaniasis using a conserved Leishmania hypothetical protein. Parasitol Int 67:344-350

Fargeas C, Hommel M, Maingon R, Dourado C, Monsigny M, Mayer R (1996) Synthetic peptide-based enzyme-linked immunosorbent assay for serodiagnosis of visceral leishmaniasis. J Clin Microbiol 34:241-248

Figueiredo MM, Santos ARR, Godoi LC, Castro NS, de Andrade BC, Sergio SAR, Jerônimo SMB, de Oliveira EJ, Valencia-Portillo RT, Bezerra LM, Goto H, Sanchez MCA, Junqueira C, Teixeira SMR, Fonseca FG, Gazzinelli RT, Fernandes AP (2021) Improved performance of ELISA and immunochromatographic tests using a new chimeric A2-based protein for human visceral leishmaniasis diagnosis. J Immunol Res 2021:5568077

Fonseca AM, Faria AR, Rodrigues FT, Nagem RA, Magalhães RD, Cunha JL, Bartholomeu DC, Andrade HM (2014) Evaluation of three recombinant Leishmania infantum antigens in human and canine visceral leishmaniasis diagnosis. Acta Trop 137:25-30

Gasteiger E, Gattiker A, Hoogland C, Ivanyi I, Appel RD, Bairoch A (2005) ExPASy: the proteomics server for in-depth protein knowledge and analysis. Nucleic Acids Res 31:3784-3788

Hasker E, Malaviya P, Gidwani K, Picado A, Ostyn B, Kansal S, Singh RP, Singh OP, Chourasia A, Kumar Singh A, Shankar R, Wilson ME, Khanal B, Rijal S, Boelaert M, Sundar S (2014) PLoS Negl Trop Dis 8:e2657

Humbert M, Costa LE, Katis I, Ramos FF, Machado AS, Sones C, Coelho EAF, Christodoulides M (2019) A rapid diagnostic test for human visceral leishmaniasis using novel Leishmania antigens in a laser direct-write lateral flow device. Emerg Microbes Infect 8:1178-1185

Kassa M, Abdellati S, Cnops L, Bremer Hinckel BC, Yeshanew A, Hailemichael W, Vogt F, Adriaensen W, Mertens P, Diro E, Van Griensven J, Van Den Bossche D (2020) Diagnostic accuracy of direct agglutination test, rK39 ELISA and six rapid diagnostic tests among visceral leishmaniasis patients with and without HIV coinfection in Ethiopia. PLoS Negl Trop Dis 14:e008963.

Kevric I, Cappel MA, Keeling JH (2015) New World and Old World Leishmania infections: a practical review. Dermatol Clin 33:579-593

Lage DP, Martins VT, Duarte MC, Costa LE, Garde E, Dimer LM, Kursancew AC, Chávez-Fumagalli MA, Magalhães-Soares DF, Menezes-Souza D, Roatt BM, Machado-de-Ávila RA, Soto M, Tavares CA, Coelho EA (2016) A new Leishmania-specific hypothetical protein and its non-described specific B-cell conformational epitope applied in the serodiagnosis of canine visceral leishmaniasis. Parasitol Res 115:1649-1658

Lemos EM, Gomes IT, Carvalho SF, Rocha RD, Pissinate JF, Martins-Filho OA, Dietze R (2007) Detection of anti-Leishmania (Leishmania) chagasi immunoglobulin $\mathrm{G}$ by flow cytometry for cure assessment following chemotherapeutic treatment of American visceral leishmaniasis. Clin Vaccine Immunol 14:569-576

Lima SA, Guerra-Duarte C, Costal-Oliveira F, Mendes TM, Figueiredo LFM, Oliveira D, Machado de Avila RA, Ferrer VP, Trevisan-Silva D, Veiga SS, Minozzo JC, Kalapothakis E, ChávezOlórtegui C (2018) Recombinant protein containing B-cell epitopes of different Loxosceles spider toxins generates neutralizing antibodies in immunized rabbits. Front Immunol 9:653

Lindoso JA, Cota GF, Cruz AM, Goto H, Maia-Elkhoury AN, Romero GA, Sousa-Gomes ML, Santos-Oliveira JR, Rabello A (2014) Visceral leishmaniasis and HIV coinfection in Latin America. PLoS Negl Trop Dis 8:e3136

Machado-de-Ávila RA, Stransky S, Velloso M, Castanheira P, Schneider FS, Kalapothakis E, Sanchez EF, Nguyen C, Molina F, Granier C, Chávez-Olórtegui C (2011) Mimotopes of mutalysin-II from Lachesis muta snake venom induce hemorrhage inhibitory antibodies upon vaccination of rabbits. Peptides 32:1640-1646

Maia Z, Lírio M, Mistro S, Mendes CM, Mehta SR, Badaro R (2012) PLoS Negl Trop Dis 6:e1484

Martins VT, Duarte MC, Chávez-Fumagalli MA, Menezes-Souza D, Coelho CS, Magalhães-Soares DF, Fernandes AP, Soto M, Tavares CA, Coelho EA (2015) A Leishmania-specific hypothetical protein expressed in both promastigote and amastigote stages of Leishmania infantum employed for the serodiagnosis of, and as a vaccine candidate against, visceral leishmaniasis. Parasit Vectors $8: 363$

Mendes TM, Oliveira D, Figueiredo LF, Machado-de-Avila RA, Duarte CG, Dias-Lopes C, Guimarães G, Felicori L, Minozzo JC, Chávez-Olórtegui C (2013) Generation and characterization of a recombinant chimeric protein $(\mathrm{rCpLi})$ consisting of $\mathrm{B}$-cell epitopes of a dermonecrotic protein from Loxosceles intermedia spider venom. Vaccine 31:2749-2755

Mohapatra TM, Singh DP, Sen MR, Bharti K, Sundar S (2010) Compararative evaluation of rK9, rK26 and rK39 antigens in the serodiagnosis of Indian visceral leishmaniasis. J Infect Dev Ctries 4:114-7

Mohebali M, Keshavarz H, Shirmohammad S, Akhoundi B, Borjian A, Hassanpour G, Mamishi S, Mahmoudi S (2020) The diagnostic accuracy of direct agglutination test for serodiagnosis of human visceral leishmaniasis: a systematic review with meta-analysis. BMC Infect Dis 20:946

Mohebali M, Yimam Y (2020) Prevalence estimates of human immunodeficiency virus (HIV) infection among visceral leishmaniasis infected people in Northwest Ethiopia: a systematic review and meta-analysis. BMC Infect Dis 20:214

Mollett G, Hinckel BCB, Bhattacharyya T, Marlais T, Singh OP, Mertens P, Falconar AK, El-Safi S, Sundar S, Miles MA (2019) Detection of immunoglobulin G1 against rK39 improves monitoring of treatment outcomes in visceral leishmaniasis. Clin Infect Dis 69:1130-1135

Okwor I, Uzonna J (2016) Social and economic burden of human leishmaniasis. Am J Trop Med Hyg 94:489-493

Pereira MR, Rocha-Silva F, Graciele-Melo C, Lafuente CR, Magalhães T, Caligiorne RB (2014) Comparison between conventional and real-time PCR assays for diagnosis of visceral leishmaniasis. Biomed Res Int. 2014:639310.

Ponte-Sucre A, Gamarro F, Dujardin JC, Barrett MP, López-Vélez R, García-Hernández R, Pountain AW, Mwenechanya R, Papadopoulou B (2017) Drug resistance and treatment failure in leishmaniasis: a 21st century challenge. PLoS Negl Trop Dis 11:e0006052.

Portela ÁSB, Costa LE, Salles BCS, Lima MP, Santos TTO, Ramos FF, Lage DP, Martins VT, Caligiorne RB, Lessa DR, Silva FR, Machado AS, Nascimento GF, Gama IS, Chávez-Fumagalli MA, Teixeira AL, Rocha MOC, Rocha RL, Coelho EAF (2018) Identification of immune biomarkers related to disease progression and treatment efficacy in human visceral leishmaniasis. Immunobiology 223:303-309

Ramos REM, Santos WJT, Magalhães FB, Diniz GTN, Costa CHN, de Melo Neto OP, Medeiros ZM, Reis CRS (2020) Assessment of a recombinant protein from Leishmania infantum as a novel tool for visceral leishmaniasis (VL) diagnosis in VL/HIV co-infection cases. PLoS One 16:e0251861.

Rezaei Z, Sarkari B, Dehghani M, Layegh-Gigloo A, Afrashteh M (2018) High frequency of subclinical Leishmania infection among HIV-infected patients living in the endemic areas of visceral leishmaniasis in Fars province, southern Iran. Parasitol Res 117:2591-2595

Rezaei Z, Pouladfar G, Ramezani A, Mostafavi-Pour Z, Abbasian A, Sarkari B, Pourabbas B (2019) Importance of $L$. infantum H2b recombinant antigen for serodiagnosis of visceral leishmaniasis. Iran J Immunol 16:311-320 
Saha S, Raghava GPS (2006) Prediction of continuous B-cell epitopes in an antigen using recurrent neural network. Proteins 65:40-48

Sanchez MCA, Celeste BJ, Lindoso JAL, Fujimori M, de Almeida RP, Fortaleza CMCB, Druzian AF, Lemos APF, Melo VCA, Miranda Paniago AM, Queiroz IT, Goto H (2020) Performance of rK39based immunochromatographic rapid diagnostic test for serodiagnosis of visceral leishmaniasis using whole blood, serum and oral fluid. PLoS One 15:e230610.

Sakkas H, Gartzonika C, Levidiotou S (2016) Laboratory diagnosis of human visceral leishmaniasis. J Vector Borne Dis 53:8-16

Santos WJT, Tavares DHC, Castro-Neto AL, Nascimento MB, Dhalia $\mathrm{R}$, Albuquerque AL, Costa CHN, Magalhães FB, Rezende AM, Melo-Neto OP (2020) Gene design, optimization of protein expression and preliminary evaluation of a new chimeric protein for the serological diagnosis of both human and canine visceral leishmaniasis. PLoS Negl Trop Dis 14:e0008488.

Sarkari B, Rezaei Z, Mohebali M (2018) Immunodiagnosis of visceral leishmaniasis: current status and challenges: a review article. Iran J Parasitol 13:331-341

Singh DP, Goyal RK, Singh RK, Sundar S, Mohapatra TM (2010) In search of an ideal test for diagnosis and prognosis of kala-azar. J Health Popul Nutr 28:281-285

Srivastava S, Shankar P, Mishra J, Singh S (2016) Possibilities and challenges for developing a successful vaccine for leishmaniasis. Parasit Vectors 9:277

Srividya G, Kulshrestha A, Singh R, Salotra P (2012) Diagnosis of visceral leishmaniasis: developments over the last decade. Parasitol Res 110:1065-1078
Takagi H, Islam MZ, Itoh M, Islam AU, Saifuddin Ekram AR, Hussain SM, Hashiguchi Y, Kimura E (2007) Short report: production of recombinant kinesin-related protein of Leishmania donovani and its application in the serodiagnosis of visceral leishmaniasis. Am J Trop Med Hyg 76:902-905

Távora LG, Nogueira MB, Gomes ST (2015) Visceral leishmaniasis/ HIV co-infection in northeast Brazil: evaluation of outcome. Braz J Infect Dis 19:651-656

Thakur S, Joshi J, Kaur S (2020) Leishmaniasis diagnosis: an update on the use of parasitological, immunological and molecular methods. J Parasit Dis 44:1-20

Torres-Guerrero E, Quintanilla-Cedillo MR, Ruiz-Esmenjaud J, Arenas R (2017) Leishmaniasis: a review. F1000Res 6:750.

World Health Organization (2018) Leishmaniasis. http://www.who.int/ topics/leishmaniasis/en/. Accessed 23 Jan 2021

Zijlstra EE, Nur Y, Desjeux P, Khalil EA, El-Hassan AM, Groen J (2001) Diagnosing visceral leishmaniasis with the recombinant K39 strip test: experience from the Sudan. Trop Med Int Health 6:108-113

Publisher's note Springer Nature remains neutral with regard to jurisdictional claims in published maps and institutional affiliations. 